\title{
When Logic Gives Out. Frege on Basic Logical Laws
}

\author{
Walter B. Pedriali
}

\section{Introduction}

How are basic logical laws (BLL) given to us? Or equivalently: how can deduction be justified? The question, however we pose it, is familiarly thorny. It is also absolutely central to the success of Frege's logicist project. Here's why. According to Frege, the Urproblem of arithmetic is the question of how we apprehend logical objects. ${ }^{1}$ It follows that the success of the logicist enterprise depends on the provision of a satisfactory answer to the question of how we can justifiedly hold certain basic truths to be logical, for it is only through those laws that we can come to grasp those objects by purely logical means. $^{2}$

And yet, for all its importance, the question of BLL-justification is one that Frege never fully addressed. At different times in his career, he considered three seemingly distinct ways of answering it, but he stopped short of endorsing or even of precisely articulating any of them.

The three suggestions are, very roughly, that the logical laws are constitutive of thought and hence that they are given to us through the activity of thinking and judging; that their authority over us flows from their being self-evident (we cognise them through some sort of rational insight, and their self-evidence entails that they are selfjustifying as well); finally, that BLL are apprehended via grasp of their constituent senses-they are true-in-virtue-of-content, and it is sense-understanding (via grasp of compositionally determined structure) that grounds their apprehension while also providing appropri-

\footnotetext{
${ }^{1}$ See the very last paragraph of Grundgesetze.

${ }^{2}$ Frege (1980: 121, 141, 191 fn. 69).
} 
ate justification for our holding them to be logically true. ${ }^{3}$

The apparent heterogeneity of these strategies could either lead us to construe them as complementary, in that we could think of them as purporting to illuminate different aspects of the same underlying epistemic problem, or it could instead suggest that they are mutually exclusive, and thus indicative of a certain wavering over this issue on Frege's part as he realised that each of those answers is in prima facie tension with some crucial aspects of his conception of logic.

At any rate, what all these answers have in common is a startling concession that at the limit of enquiry, at the point where we ask about the most fundamental features of the structure of thought, logic has got to give out. ${ }^{4}$ Logic, Frege tells us, regulates thought-transitions, but there is no transition to BLL over which logic could legislate. Some other form of rational constraint must be in place there. But of what kind?

The puzzle is familiar from other areas of enquiry. ${ }^{5}$ In the philosophy of logic, though, it takes on a specific urgency, particularly so in Frege's case, given his dual commitments to the universality of logic (i.e. to logic being the science of widest generality) and to a firm rejection of any form of psychologism (i.e. to the banishing of any view that would make logic hostage to the contingent cognitive processes of thinkers).

On the face of it, those commitments seem to leave little space for an answer to our question that would jointly satisfy them. Any suggestion we might make regarding the rational constraints presiding over the apprehension of BLL will clash, or so it appears, with (at least) one of those two key components of his conception of logic (if logic cannot regulate transitions to BLL, then the universality thesis seems threatened; if e.g. we try to invoke constitutivity principles regulative of all thinking to explain those transitions, we risk running afoul of the anti-psychologist constraint).

My purpose in this chapter is to rehearse these three broad lines of response to our Urfrage and assess whether they build up to a coherent picture of the epistemology of BLL, in particular a picture that

\footnotetext{
${ }^{3} G L(\$ \$ 14,26) ; G G$ (xvi-xvii); GL (\$\$2, 90), GG (viii, 253); and (1923a: 405; 1980: 183; 1914a: 247) respectively. I shall use three abbreviations, namely, ' $B G$ ' for Begriffschrift, 'GL' for Grundlagen and ' $G G$ ' for Grundgesetze.

${ }^{4}$ Frege (1879/1891: 3, 6; 1906a: 175).

${ }^{5}$ For just one example, see O’Neill (2000: 11).
} 
would sit well with the rest of Frege's views. ${ }^{6}$

The structure of the chapter is as follows. I first outline an argument for the essential basicness of the fundamental laws of logic. In the following three sections I then move on to consider the three approaches I have just introduced, as well as a fourth one (in $\$ 5$ ), proposed by Burge (1998) and Reck (2007), which I dub "pragmatic foundationalism" and that proposes to somehow unite them all in one cohesive picture. In the last section, I put forward a modified version of this last proposal which I think is more in keeping with Frege's own framework.

\section{The Architectural Argument}

First, then, let me very briefly review what I shall call the architectural argument for the obtaining of basic logical knowledge. The major premise in the argument is that if there is to be any knowledge at all, there have to be, on pain of regress, some truths which are not derived from other truths (the game of asking for reasons cannot go on ad infinitum, we are told). 7 On the plausible assumption that we do have knowledge of logical facts (e.g. entailments and so forth), the argument concludes that we have (and must be credited as having) knowledge of basic (i.e. underived) logical truths.

Those truths, given the argument, are exempted from normal standards of justification. Happily, the architecturally-induced exemption is wholly appropriate since BLL are epistemically unimprovable anyway-no inferentially derived justification could strengthen their epistemic standing. If so, we might just as well conclude, as Frege

\footnotetext{
${ }^{6}$ Opinion is divided as to whether Frege has said enough for us to reconstruct his views on the matter with sufficient textual authority on our side. Burge (1998: 322) and Heck (2012: 34) think he has. Ricketts (1986: 74, 81; 1996: 124; 1997: 174), Weiner (1986: 22), Goldfarb (2001: 301) disagree. For general doubts concerning the point of providing BLL-justification see Dummett (1991c: 204), Heck (2012: 28), Stanley (1996: 122-3), Blanchette (2012: 153) and Sullivan (2005: 101). Haack (1976) and Greimann (2014: 276) declare BLL-justification to be impossible. Nagel (1997: 62) thinks that it is impossible coherently to challenge BLL. Sullivan (2011: 160) and Enoch (2011: 220) are unconvinced by this kind of response. Finally, van Heijenoort (1967: 326), Ricketts (1985) and Weiner $(1990,2001,2002)$ have suggested elucidation is the best the Fregean can do in this area.

${ }^{7}$ See e.g. Locke (1689/1975: IV.vii.\$19), Frege (1879/1891: 3; GL: $\$ 3$, fn. 1; 1914a: 204; GG: vi); Russell (1903/1996: \$17), Dummett (1991c: 245-6), Boghossian (2001: 239ff.; 2003: 271), Hale (2002: 279), Peacocke (2004: 72; 2008: 156-8), BonJour and Sosa (2003: \$1.2) and Russell (2008: 197).
} 
himself did, that BLL neither need nor admit of external epistemic support. In addition to their privileged architectural role, then, BLL are also declared to be self-justifying because epistemically speaking they are internally grounded.

For our purposes, I'll grant that the argument carries weight. We'll shortly be considering how the self-justifying claim (a claim that is somewhat independent of the architectural argument) could be made more precise. Our first task, however, is to find out how we can identify the class of BLL.

\subsection{The Marks of the Logical}

What are the distinguishing features of BLL? We can attribute to Frege a cluster theory of BLL gathering together those marks of the logical that are singly necessary and jointly sufficient for something to count as a BLL.

On Frege's view, then, BLL are

maximally general they apply to all areas of scientific inquiry-any area where the question of truth arises; ${ }^{8}$

non-proof-apt since in the case of BLL proof is neither available nor required: it is a category mistake to think they could be proved; 9

not analytic for they are analytically basic; ${ }^{10}$

self-evident in the three senses of being i) self-standing in the natural order of truths, ii) self-justifying in epistemic space, and iii) epistemically pellucid, i.e. their unconditional truth is immediately

\footnotetext{
${ }^{8}$ Frege (1897b: 128; 1885a: 112; 1906c: 338). See Burge (2000: 369), Goldfarb (2010: \$1), Blanchette (2012: ch. 6) and Heck (2012: 35-6) for discussion.

${ }^{9} G L(\$ 3)$. In a particular (epistemic-driven) sense of 'proof' of course. We can always prove BLL. But this is a system-relative notion of proof. The notion of unprovability operative in Frege is instead an absolute one, and one to do solely with epistemic standing (no formal derivation of BLL in a system of proof could improve that standing). For just one example of the move from unprovability to logical basicness, see Frege (1891: 142). For the converse thesis, see e.g. GG (II, $\$ 60)$.

${ }^{10}$ That BLL are not Frege-analytic may strike one as surprising. But Frege-analyticity is proofinvolving (see $G L \$ 3$ ). It follows that BLL cannot be analytic, for if they were they would then be provable, and thus contradict the non-proof-aptness constraint. See Dummett (1991b: 24), Burge (1998: 322; 2003) and Sullivan (2004: fn. 85) for discussion. Contra Benacerraf (1981: 45), then, Frege's analytic/synthetic distinction is not exhaustive.
} 
obvious to reflection for a thinker who fully grasps them; ${ }^{11}$

all-encompassing in the sense of being proof-theoretically complete, that is, they contain within themselves, "as if in a kernel", the entire reasoning edifice (they surveyably contain the class of their syntactic consequences); ${ }^{12}$

demonstrably fruitful their all-encompassing nature must be verified and made manifest in the actual exercise of inference within a range of derivational systems. ${ }^{13}$

In the next three sections I focus in turn on the three main lines of response to our main question. As we shall see, the marks of the logical that I have just outlined will play a crucial part in the attempt to sharpen up each of these replies.

First, though, let me take a very brief detour on the question of unprovability.

\subsection{BLL and the Absence of Proof}

For Frege, then, BLL are essentially non-proof apt. By saying that structural unprovability is one of the constitutive marks of BLL, however, we haven't yet shown that the in-principle unavailability of proof for the basis won't infect the entire construction. From the preface to Begriffsschrift onwards, Frege steadfastly held that in mathematics justification depends on proof. But if BLL admit of no proof, how can unjustified (and indeed unjustifiable) justifiers legitimately be said to provide justification for the whole of mathematics? To parry this worry, we need to show that even without proof on their side BLL can still enjoy some kind of rational justification, indeed, enough justification to get the justification game going. This is in fact the task that will occupy us for the rest of this essay.

As we saw earlier, according to Frege when it comes to BLLjustification logic has to give out. Now, this could either be because

${ }^{11} G L(\$ 17)$, Frege (1899-1906: 168; 1923a: 405.)

${ }^{12} B G(\$ 13), G L(\$ \$ 17,88), G G(I I, 149)$, Frege (1885a: 113; 1914a: 204-5).

${ }^{13}$ This is, as it were, the converse thesis of logicism: given that arithmetic is reducible to logic, BLL must also provably contain exactly the amount of mathematics that we want to prove. If they do, then our initial choice is confirmed as correct. I have not included the mark of surveyability (Übersichtlichkeit, see GL $\$ 5$ ), that is, unimpeded accessibility to Reason, which I think of as a feature of self-evidence. 
there can be no such thing as a thought-transition to BLL or because the transition, although still subject to some sort of normative constraint, is not one that logic can regiment (precisely because of the non-proof-aptness of BLL). Call these transitions, of either kind, BLLentry points. They are, in effect, the entry points of rationality. ${ }^{14}$

Under the first option, cognitive access to BLL would be radically immediate, perhaps in a manner analogous to perception-that BLL are true is something that we can see. ${ }^{15}$ But this won't do because Frege is notoriously insistent that mathematics be grounded in a purely logical source of cognition, a source that, unlike perception, is capable of thoroughly intersubjective assessment. ${ }^{16}$ If a form of insight is called for, it had then better be some form of rational insight or else it would be rationally blind. In the next section, we'll be rehearsing a conception of BLL-entry points along these lines

Under the second option, access to BLL is not immediate, but the transition to them is not inferentially mediated either. It still is normatively constrained, though. We'll explore this option in $\$_{3}$.

There is also a variant of the first option, one that rejects as incoherent the very idea that there could be such a thing as an entry point to rationality (or equivalently, that those points could coherently be said to be accessible). We'll deal with this option in $\$ 4$.

Before we move on, let me quickly summarise the constraints we are working under. Firstly, a Fregean account of BLL-justification must respect the universality thesis without violating the antipsychologism requirement. Secondly, the account needs to show how BLL can justifiedly be grasped either in virtue of sui generis thoughttransitions to them or in virtue of some sui generis features of their content or of their architectural role.

Finally, note that what is of particular interest in considering the three lines of response is the way in which thought-transitions and content-grasp will interact, as we shall see in due course.

We now begin our discussion of BLL-entry points by examining Frege's notion of self-evidence.

\footnotetext{
${ }^{14}$ Similar notions are discussed in Sellars (1954), Kremer (2001: 51-2) and Sullivan (2002: 64).

${ }^{15}$ See e.g. Wittgenstein (1914-16/1998: 100) and Tractatus (\$5.13, \$6.122), as well as Russell (1903/1996: §45). See also Parsons (1965: 172).

${ }^{16}$ Frege $(1924 / 25)$.
} 


\section{Self-evidence}

Of all the marks of the logical, self-evidence is the feature most often invoked by Frege to identify a BLL. ${ }^{17}$ Frege employed a number of different terms to denote the concept that is rendered into English as self-evident. The most important are selbstverständlich, einleuchtend and unmittelbar klar, and they neatly characterise the three key features that Fregean self-evidence possesses.

In the first instance, self-evidence is unmediated recognition of the privileged epistemic status of BLL (BLL are given to us without external mediation). ${ }^{18}$ Secondly, self-evidence makes BLL-content shine through its linguistic garb (grasping the form of a BLL is grasping its content). ${ }^{19}$ These two features jointly ensure that, in entertaining a BLL, apprehension of its content and appreciation of its truth are acts that are not even notionally separable. To grasp the content (via its form and its form alone) is to see that it expresses a maximally general truth of the appropriate kind.

Finally, self-evidence is epistemic self-standingness. ${ }^{20} \mathrm{BLL}$, that is, stand on their own epistemic feet, as it were. They are self-justifying in that they furnish their own justificatory grounds-BLL are true in and of themselves. ${ }^{21}$ This is so because their truth does not depend on that of other propositions (and it is precisely the unavailability of proof for BLL that shows their epistemic independence). ${ }^{22}$

\footnotetext{
${ }^{17}$ It has often been remarked that Frege's persistent doubts concerning Basic Law V were due to its lack of self-evidence. See the afterword to Grundgesetze and Frege (1906b: 182). See Burge (1998: 348, fn. 21), Heck (2012: 32-4) and Schirn's contribution to this volume for discussion. Much of the credit for a revival of interest in the notion of self-evidence arguably goes to work done in Burge (1998) and Jeshion (2001, 2004). For criticism see Weiner (2004) and Shapiro (2009).

${ }^{18}$ That's the umittelbar bit. The common English translation as 'immediate' suggests unwanted temporal connotations.

${ }^{19}$ This is the einleuchtend aspect. This aspect of self-evidence is essential to Frege's idiosyncratic conception of logical consequence. See Goldfarb (2010: \$1) and Blanchette (2012: 142, 150) for discussion. Self-evidence thus construed should not be confused with obviousness (compare Quine (1970: 82) and Haack (1978: 235-6)). Obviousness is unearned and defeasible. Genuine self-evidence on the other hand may, and typically does, require hard work (see the introduction to $G L)$.

${ }^{20}$ This is the selbstverständlich aspect. In the light of what I'll say in the next section, a good (if rather free) translation would be: 'internal to the operations of the understanding', or even: 'due to the powers of the understanding alone'.

${ }^{21}$ See Frege (1976: 62) where selbstverständlich and von selbst wahr are used interchangeably.

${ }^{22} G L(\$ 2)$ tells us that one of the aims of proof is to bring out the order of dependence among truths. In the limit, unprovability is thus proof of independence.
} 
The first two features belong to what is natural to call subjective self-evidence (or thinker-relative self-evidence). By contrast, the third feature seems best characterised as objective (or thinker-neutral) selfevidence. ${ }^{23}$ Objective self-evidence is, again, an architectural feature of the Sätze an sich, which the subjective uptake of that feature merely reflects. And one can earn one's right to treat a given BLL as subjectively self-evident only after having established its objective selfstandingness. ${ }^{24}$

Clearly enough, on the conception sketched in this section there is no proper thought-transition to BLL involved. All the work is done by the act of content-grasp, an act which is also, and eo ipso, an act of truth-recognition. ${ }^{25}$

A highly legitimate complaint at this stage will be that self-evidence, thus construed, is really little more than a convenient label for a phenomenon (the epistemology of BLL) that still resists full characterisation. Beyond indulging in suggestive talk of rational insight, ${ }^{26}$ that is, we haven't really done much to sustain the idea that content-grasp of this kind is rationally sanctioned, we haven't really said what kind of special act of intellection the notion of self-evidence is supposed to capture. And, rather embarrassingly for the Fregean, unless we can properly flesh out the notion of objective self-evidence, all that we have on hand is subjective self-evidence, and with it, the loom-

${ }^{23}$ For this distinction see Burge (1998) and Jeshion (2001). See also Audi (1999: 214).

${ }^{24}$ In $\$ 5$ we’ll examine one way of doing that. Note that for Frege subjective self-evidence is defeasible. It is however still a notch-up from obviousness, which is a merely psychological notion, whereas subjective self-evidence, although agent-relative, is not (the self-evidence involved is with respect to purely logical concepts, and thus untainted by specific psychological processes).

${ }^{25}$ An exception, then, to Frege's (1918-19: 355-56) insistence that content-grasp and acknowledgement of truth be kept separate.

${ }^{26}$ Jeshion (2001: 956) speaks of "rational recognition of truth", Burge (1992: 299-302) of BLL being apprehended "purely through reason". Field (2000: 363, fn. 6) thinks that talk of this kind amounts to an "obscurantist redescription". It's hard to disagree. There are two recent attempts to flesh out the notion of self-evidence as rational insight in terms of a logic faculty thesis. Frege might have been sympathetic to some aspects of these proposals. See e.g. Frege (1906b: 181) where he explicitly speaks of "logical capabilities" (logische Fähigkeiten) enabling us to grasp extensions. See also (1924/25: 269; 1984: 235; GL: $\$ \$ 2,90$.) The two (significantly different) proposals are Evnine (2001) and Hanna (2006). Whatever their independent merits, these proposals are incompatible with a fully Fregean epistemology of BLL. For Frege, the posited features of the logic faculty must be highly formal and make no reference to empirical findings-they should build up to a theory of pure competence, with no infiltration from performance considerations at all (see e.g. Frege (1897b: 145-9)). Both proposals fail on this ground alone. 
ing spectre of psychologism. ${ }^{27}$ More specifically, the trouble with a psychologist gloss of the hold that BLL exert on our thinking is that it leaves the normative aspects of logic largely unexplained. On the story as told so far, BLL appear to force themselves on $u s$ in a manner that leaves us powerless to articulate the precise nature of that hold. And one will of course want to ask: what has this got to do with logic?

The questions we need to face to allay this worry are: $i$ ) on what rational basis can we recognise the privileged epistemic status of BLL qua self-evident truths, and ii) in virtue of which objective properties do BLL enjoy that status.

Let's now examine an account that tries to answer both questions by cashing out the notion of self-evidence in terms of understanding.

\section{Sense-based Understanding}

It wasn't until a little throwaway remark in his last published work, 'Compound Thoughts', that Frege finally gave a substantive, if fleeting, gloss to his notion of self-evidence. ${ }^{28}$ His suggestion there was that the (objective) self-evidence of BLL manifests itself through the transparency of compositionally determined sense. It is a familiar Fregean thesis that we grasp the sense of the whole by compositionally computing the sense of its constituent parts. ${ }^{29}$ Equally familiar is the idea that sense is, in general, the truth-conditional contribution made by an expression under embedment. In the case of BLL, then, the computation of their sense from its constituent senses brings forth the judgement that the truth condition thereby determined is necessarily satisfied. And that this is so is immediately evident to anyone who properly and fully grasps that sense. In other (very Fregean) words, full understanding of sense is equivalent to taking the step to the judgement regarding truth value, and indeed to the acknowledgement that BLL name the True in all conceivable cases. ${ }^{30}$

\footnotetext{
${ }^{27}$ Tractatus $\$ 6.1271$ conveys the young Wittgenstein’s disappointment that a thinker “as exact as Frege" should have rested his epistemology of BLL on an apparently psychological notion. The complaint is, I think, unwarranted (see fn. 24), but it needs work to show why it is so.

${ }^{28}$ Frege (1923a: 405). See also the earlier (1914a: 247) where we even find a proto-version of the meaning-variance argument made familiar by Quine (1970: 81).

${ }^{29}$ Frege (1980: 79; 1914a: 225).

${ }^{30}$ See e.g. $G G(I, \$ \$ 12,18)$. A sense-based explanation of self-evidence would obviously have a further theoretical advantage: it would illuminate the central theoretical role played by the
} 
In terms of our previous discussion, the picture that now emerges is one whereby we do countenance a transition to BLL, namely, that effected by the sense-computation carried out by competent thinkers. Moreover, the previously generic appeal to an underspecified rational faculty that supposedly powers the mechanisms at play in the phenomenology of self-evidence has now been replaced by a (relatively) precise notion, namely, that of sense. ${ }^{31}$ And with the sense-based view at hand we are also in a position to give reasons for our epistemic attitude towards BLL: it is our beliefs about constituent senses and their mode of combination that rationally sustain our belief about the complex sense (that it is a truth of the appropriate kind).

So, by appealing to sense we can now give a neat account of BLL-entry points as themselves rationally grounded, with the added advantage that anti-psychologist anxieties are now altogether side-stepped (on the Fregean account, senses are objective, nonpsychological entities).

A further benefit is that under this proposal the universality thesis too is (by and large) preserved. This is so because with the notion of sense on board we have gained a different notion of proof, namely, what is nowadays called a meaning-theoretic proof, and what we should call, within a Fregean framework, a sense-theoretic proof. ${ }^{32}$ We can then say that BLL-justification is logic-involving but noncircular. Here's how.

First, let's note that while any system-relative proof-theoretic demonstration of the necessary truth of BLL would be epistemically circular (whether or not viciously so), a sense-theoretic proof that showed how the compositionally determined sense necessarily denotes the True would not be circular. On the contrary, epistemically speaking it would be highly informative, since it would disclose (and deploy) essential conceptual commitments incurred by any competent concept-mongering creature which are not immediately appar-

sense/reference distinction in Frege's later work (see Simons (1992) for discussion). Indeed, we could well say that while reference is essential to logic (Frege 1892/1895: 133), sense is essential to its epistemology.

${ }^{31}$ Actually, what does the job is sense-grasp, a notion less precise than that of sense but still more precise than the notion of rational insight.

${ }^{32}$ For some examples of meaning-theoretic proofs, see e.g. Davies (1981) and Lepore and Ludwig (2007). Note that a sense-theoretic proof would not state contingent facts about a specific language but rather non-contingent, language-independent facts about the composition of specific thoughts. 
ent from the (unembedded) grasp of the concepts involved. ${ }^{33}$ It is only through their combination, that is, that BLL-constituent senses generate justifying reasons. Of course a sense-theoretic proof would still employ BLL-derived rules (e.g. modus ponens, conjunction introduction, and existential generalisation) but those rules would not be doing the fundamental explanatory work in the proof. Bottomup sense-determination (from the constituents to the whole, that is) would. The universality thesis would thus be neatly preserved, or so I'd argue, since logic is still involved in the BLL-proof by guiding and policing its proper execution. It does so without circularity worries, however, for the proof is sense-driven, and logic is taking, as it were, a back seat.

This all sounds very promising indeed, nicely meeting all our constraints and providing a very Fregean answer to our problem.

Unfortunately, it seems to me that we have however created a new problem. A sense-based notion of self-evidence gives rise to a rationally constrained transition to BLL (the sense-computation could demonstrably go wrong), and that's a very welcome result. But we have also retained a more traditional form of immediacy, this time at the level of sense-grasp-there is no mediation, inferential or otherwise, between sense-grasp and truth-evaluation. And in my view that's where trouble arises.

To anticipate, the problem is two-fold, affecting the claim (which needs to be in place for the account to work) that both the constituent and the complex BLL-senses are fully transparent to reasoners and, secondly, the claim that the acknoweldgement of truth is co-occurring with the act of full sense-grasp. More precisely, the problems are that $i$ ) BLL-senses cannot bear the cognitive and prooftheoretical weight required of them; and that ii) even if they could bear it, the posited immediacy (the fact that to understand a given BLL is to unconditionally grasp its validity) makes it impossible even to entertain doubt as to validity in general (the process of reflective self-scrutiny with respect to BLL has now become an incoherent notion, that is). ${ }^{34}$

\footnotetext{
${ }^{33}$ This is perhaps the way in which Brandom $(1994,2008)$ and Lance and Kremer $(1994,1996)$ can be seen as proper elaborations of the Fregean project.

${ }^{34}$ Frege (1923a: 405) seems to miss this point, where he suggests that negating a BLL does not give rise to nonsense as long as one does not assert the negated proposition-the sense-based proposal he makes in the next paragraph obliterates any distinction between thought-grasp and thought-
} 
Let me take these problems in turn. Regarding i), note that the sense-based proposal treats BLL as content-analytic (true-in-virtueof-content). But it is unclear $a$ ) whether we have an appropriately firm grasp of the constituent senses involved (for instance, of the notion of value-range in Basic Law V); ${ }^{35}$ b) whether there is a definite answer to the question of how (and if) we can legitimately pack into the sense of a connective exactly the right amount of content that is required to fix the class of validities; ${ }^{36}$ and finally $c$ ) whether the sensetheoretic proof would escape familiar undecidability issues (the class of theorems supposedly contained within the content of the BLL is not decidable and is hence unsurveyable). ${ }^{37}$

The first round of difficulties, then, is that a sense-theoretic account would be presupposing that we grasp the sense of the fundamental notions of logic and arithmetic with a clarity that those notions do not, as a matter of fact, afford. Note that this is as true of contemporary mathematicians as it was of Frege's. For instance, it doesn't seem as if there is (or will ever be) a clear answer as to the question of whether or not non-well-founded sets are sets properly so called, nor is it clear whether e.g. in adjudicating between competing large cardinal axioms we are being guided by the content of the concept of set or simply determining it afresh. But if we are (radically) unclear as to the constituent senses of BLL, it is obscure how we could possibly derive from them a clear grasp of their complex sense.

And in any case, even if we did grasp the constituents clearly and

assertion in the case of BLL-thoughts. On the view he sketches, it would be irrational to grasp a BLL-thought and not assert it.

${ }^{35}$ We also lack firm criteria, by Frege's (1914a: 210) own admission, to establish when two senses are the same (see e.g. Benacerraf (1981: 46), Dummett (1991b: 35) and Blanchette (2012: ch. 4) for discussion). If so, it is unclear how we can sensibly speak of the complex sense as being "built up" out of its constituents in the absence of a proof that the meaning function for the whole returns the same value as the compositional function of its parts.

${ }^{36}$ As witnessed by contemporary debates on logical inferentialism over whether we ought to include as part of the meaning of a connective just a (possibly proper) subset of the operational rules or the sub-structural rules as well. Similar problems arise with respect to e.g. negation in debates around dialetheism. See e.g. Priest et al. (2004: 4), Priest (2006: 122) and the Slater (2007)/Priest (2007) exchange.

${ }^{37}$ See Gödel (1944: 138-40) and Benacerraf (1981: 65). We might bite the bullet (as Gödel (1951: 320-21) does) and accept that content-analytic truth might be undecidable. Given Frege's cluster theory of the logical, though, that option is not available (e.g. surveyability would be lost). The further, familiar and more general objection that the reduction would be circular is due to Poincaré. See e.g. Parsons (1965: 167-171) for discussion. 
distinctly, we would still face the undecidability worries regarding the proof-theoretical status of the derivation recalled above. It follows that sense cannot be the sole vehicle of grasp of validity (it cannot bear the required epistemic weight all by itself).

A further obstacle bars the way and this time the problem is that the sense-theoretic proposal would be doing too much. ${ }^{38}$ If to fully sense-grasp a BLL is eo ipso to unconditionally recognise its validity, it follows that even a temporary suspension of validity-recognition would immediately entail that the content in question is no longer being grasped, that in withdrawing acknowledgement of its necessary truth-value we no longer understand what the BLL actually says.

The trouble here is that in assessing the putative validity of a given BLL (a task that seems rationally required to properly verify the good standing of one's BLL-belief) a gap is required for the assessment to take place coherently. We need a temporary suspension of forced acceptance of validity, a suspension that must however leave understanding intact-or else we couldn't even know what we are testing for validity, for as soon as doubt is raised one is no longer thinking of the same law. ${ }^{39}$

By removing this gap, BLL-immediacy has wiped out the possibility of metatheoretical reflection, and more generally of reflective normative ascent. ${ }^{40}$

How could a Fregean respond? The most promising reply is to invoke incomplete understanding, that is, incomplete grasp of the sense involved - the hesitant (or deviant) thinker is seeing the sense "as if through a mist". ${ }^{41}$

But now new difficulties arise. For a start, it seems prima facie unpromising to say that perfectly competent logicians who challenge established logical laws do not understand the senses of the expressions involved. ${ }^{42}$ They deny validity precisely because they under-

\footnotetext{
${ }^{38}$ The obstacle has been much discussed in a different context, namely, the Boghossian (2003)/Williamson (2003) controversy. See my (2012: \$6) for discussion.

${ }^{39}$ There are moves available here, such as appealing to a distinction between concept-possession and one's conception of that concept (see e.g. Higginbotham (1998: 150). Other cognate distinctions are in Peacocke (1992: 29), Burge (1993: 460) and Horwich (2010: 242). None of these moves, however, are compatible with Frege's austere conception of the sense of logical notions.

${ }^{40} \mathrm{I}$ modify a term from Owens (2000: 12). See also Korsgaard (1996: 92).

${ }^{41}$ Frege (1914a: 209-10, 215-22).

${ }^{42}$ Peacocke's (1987: 163) bites the bullet here, claiming that unless one "appreciates" that $p$ and $\neg p$ are incompatible, one doesn't understand negation
} 
stand what the BLL states.

Moreover, appeal to incomplete sense-grasp poses a dilemma for the Fregean, for it either generates another regress or it forces a radical revision of the notion of sense. The revised notion, however, will no longer be suitable to explain BLL-grasp. Here's the dilemma. Uncertainty about sense can either be uncertainty about its content or about the way it is presented to us.

Suppose we go for the first horn. By definition, Fregean sense is nothing over and above being a reference-determining algorithm. 43 But then if we are confused about the content of a particular sense, we must be missing out on some crucial reference-determining element, something that is ex hypothesi essential to the sense being the sense it is. On this horn then we have to sacrifice the defining condition of the notion of sense, since fuzzy grasp of a given sense could not leave intact its reference-determining properties. A fortiori, it could not carry out its task of providing BLL-justification.

If we move to the other horn, we find that things are just as uncomfortable there. On that horn, the proposal is that in cases of incomplete understanding what we are unclear about is not the content of the sense but the way it is given to us. The assumption is now that senses too come with modes of being given attached to them. And we are thus off on a regress of modes of being given, one that we seem unable to block in any non-arbitrary way. ${ }^{4}$

If these difficulties are as hard as I've made them out to be, it seems as if a sense-based gloss on the notion of self-evidence cannot explain how BLL are given to us without incurring unacceptable theoretical costs.

It is now time to turn to the third line of response to our question, a line that posits a constitutive role for logic with respect to judgement and thought.

\section{The Constitutivity of Logic}

Earlier on, I rehearsed the complaint that it is unclear how a merely impressionistic conception of self-evidence could account for the

${ }^{43}$ More cautiously: a reference-seeking algorithm. See e.g. Frege (1892/1895: 136; 1892: 174).

${ }^{44}$ See Bell (1987), Dummett (1986, 1989, 1990a,b), Beaney (1996: 219-20), Kremer (2010: 28689) and Burge (2012: 574-75). 
normativity of logic; a little later I objected to the more precise, sensebased proposal because it left no gap between grasp of and critical stance to BLL. In this section, I go over a proposal that is prima facie spectacularly vulnerable to both complaints. This sounds rather unpromising, but the proposal is one that Frege considered, and more than once too. It is also a proposal that gets very close indeed to the crux of the matter. We'd better give it a fair hearing then.

Our third proposal is that BLL are justified because they are constitutive of thought: to think, the suggestion goes, is to reason in accordance with BLL.

There are remarks that strongly support attributing a view of this sort to Frege:

We have only to try denying any [BLL], and complete confusion ensues. Even to think at all seems no longer possible. [...] The truths of arithmetic govern [...] all that is thinkable.

The task we assign logic is [...] that of saying what holds with the utmost generality for all thinking.

[BLL] are the most general laws, prescribing how to think wherever there is thinking at all. 45

The last claim seems particularly clear in taking thinking, properly so called, to come into existence only when BLL are obeyed. It thus seems as if BLL are not really laws at all. Rather, they are the conditions for the possibility of thinking (no BLL, no thinking) - and if that seems too strong, one can weaken the claim and say that BLL are constitutive of genuinely rational, i.e. truth-oriented discourse. ${ }^{46}$ Either way, BLL set the standards that determine when our movements between thoughts count as movements done for a reason, indeed movements done in the light not just of $a$ reason, but of Reason itself. 47

${ }^{45} G L$ (\$14); GG (xv), my emphases. MacFarlane (2002: 35) and Taschek (2008: 384ff.) read Frege as committed to a constitutive view of BLL. Greimann (2014: 277-78) disagrees.

${ }^{46}$ As suggested in Greimann (2014: 278). Taschek (2008: 384) proposes that the constitutivity claim is with respect to being a thinker (a thinker is someone who acknowledges the normative hold of BLL). For his part, Frege (1879/1891: 4) is quite clear that BLL are not those "in accordance with which we actually draw inferences", or else, he adds, "we could never draw a wrong inference". The sense of thinking involved in those passages where Frege toys with a constitutive accounts, then, is best read as a highly idealised one.

${ }^{47}$ See e.g. the end of $\$ 26$ in GL. At least since Harman (1986) objections have been raised against any straightforward identification between logic and rationality (or against treating logical entailment as a trigger for demands of rationality). For a recent discussion see Broome (2013). I lack the 
In the preface to Grundgesetze, however, Frege appears to backtrack, once again because of anti-psychologist worries:

Stepping outside logic, one can say: our nature and external circumstances force us to judge, and when we judge we cannot discard this law-of identity, for example-but have to acknowledge it if we do not want to lead our thinking into confusion and in the end abandon judgement altogether. I neither want to dispute nor to endorse this opinion, but merely note that what we have here is not a logical conclusion. $4^{8}$

Note that here Frege reminds himself (and us) of the point made in his $(1879 / 1891: 3)$ that logic has got to give out when it comes to assessing the role of BLL. The constitutive arguments he'd previously sketched are not ones that, Frege thinks, logic could endorse, or indeed have any use for. Why not? Well, largely, or so it seems, because talk of constitutivity could at best establish that we find modes of reasoning supposedly constituted by different BLL utterly incoherent, indeed beyond imagining. But this seems to disclose only facts about our psychological make-up rather than provide a genuine explanation of the fact that the normative hold of BLL must extend, and be seen to extend, to creatures with different psychological underpinnings. If so, the conclusions that one could establish via constitutivity arguments are powerless to provide absolute grounding for BLL. At most, they'd provide perspectival grounds, grounds that would be binding only for beings such as ourselves. The boulder-like unmovability of BLL, then, would be diluted to a relative unmovability, one to be explained solely in terms of the limits of what is conceivable to us.

It thus seems as if when logic gave out it called out to epistemology for help but it was psychology that instead answered the call. In the remainder of this section, I want to sketch an account in terms of constitutivity that might quell Frege's anxieties. The way out, I think, is to say that BLL are constitutive of something, namely, judgement, that is wholly independent of our cognitive make-up or of contingent aspects of our situatedness, or indeed of any situatedness.

That BLL are constitutive of judgement (taking judgement to be

space for a fuller discussion of these important issues, but I think Frege's account can avoid those objections, in that Fregean reasoning is everywhere reasoning from proved propositions.

${ }^{48} G G$ (xvii), my emphasis. See Ricketts (1986: 68), Conant (1991) and Shieh (2002: 101-03) for discussion. 
an objective, non-psychological notion) is something Frege clearly seems to have held. Consider the following claims:

To recognize something as true is to make a judgement.

Like ethics, logic can also be called a normative science. How must I think in order to reach the goal, truth? We expect logic to give an answer to this question.

Logic is concerned with the laws of truth, [...] not with the question of how men think, but with the question of how they must think if they are not to miss the truth.

[BLL] set the standards for our thinking if it wants to attain the truth. 49

One might think that the last two remarks support attributing to Frege a view of logic as purely instrumental reason (logic specifies the means of achieving one's alethic ends but is unable to give categorical reasons for the pursuit of those ends). But with the first remark in mind, it seems clear to me that Frege did think that BLL are constitutive of judgement. Judgement is truth-recognition, and only BLL-observance can give rise to that. So, while thinking is possible without judgement (1897a: 139) - that is, without aiming at truth and hence without regard for BLL-judgement itself would not be possible at all without adherence to BLL, because to judge is to aim at truth and only BLL can give guidance in that endeavour. Indeed, a few lines below the tentative passage in the Grundgesetze preface cited above, Frege abandons any hesitation and confidently claims that:

Whoever has once acknowledged a law of being true has thereby also acknowledged a law that prescribes what ought to be judged, wherever, whenever and by whomsoever the judgement may be made.

The activity of judging, that is, can (and must) be explained with no reference whatsoever to the idiosyncrasies of the judger. With the BLL at hand, that is, we can define judgement in absolute, nonthinker-relative terms.

It is however true that Frege (1919: 273) seems to qualify that unusually confident statement:

\footnotetext{
${ }^{49}$ Frege (1879/1891: 7, 1897a: 139; 1897a: 128; 1897a: 149; GG: xvi). Still on the same page from the preface to Grundgesetze Frege equates the laws of being true with the laws of "what ought to be thought", i.e. the laws of how to judge.
} 
Both grasping a thought and judging are acts of a knowing subject and belong to psychology. Both acts, however, involve something that does not belong to psychology, namely, the thought.

I think Frege was again being overcareful here, ${ }^{50}$ but I also think that one can take him at his word and restate the constitutivity thesis with respect to objects of thought (with respect to thought as thoughtcontent, that is). ${ }^{51}$

So on this new reading of the thesis, it is not (just) that without BLL in place there could be no rational thinking, or no judging at all. Rather, without them there could be no thoughts, no order of truths, no content at all. Why? Because the individuation conditions for thoughts are given in terms of truth-determination (note: of how a thought determines its truth condition, not just of what truth-condition it determines) and BLL define what it is to determine truth in a particular way. Individual BLL determine particular ways of truth-determination (both for the base and for the compositionally derived complex expressions) while BLL taken as a corporate body unfold "the content of the word 'true" ". 52

Accordingly, I propose that the appropriate reading of the constitutivity thesis is to be given in terms of content-constitutivity rather than agent-constitutivity. ${ }^{53}$ This is the only way, it seems to me, to respect both the anti-psychologism constraint and the universality thesis (logic is constitutive of all that is thinkable, that is, of thoughtcontent itself).

On the agency-constitutive reading, any case of disagreement over the status of a particular BLL is a case where as soon as we give up the law we cease being reasoners altogether. We thus have the paradox that in performing an act (the denial of a BLL), we thereby give up on

\footnotetext{
${ }^{50}$ Frege (1879/1891: 5-6) gives a more reasonable take on the matter. All that is required is that one's account not include "a relation to the judging subject", as $G G$ (xvi) puts it.

${ }^{51}$ Clearly, any version of the thesis must be taken to apply to BLL considered as a whole and not individually, for while e.g. Identity is plausibly constitutive in a general way, Basic Law V can at best be claimed to be constitutive only with respect to mathematical thought/thinking.

${ }^{52}$ Frege (1879/1891: 3). I lack the space to deal with another crucial aspect of the relationship between BLL and judgement, namely, the question of Frege's conception of the essence of logic and of the role of assertion in revealing that essence. See Frege (1879/1891: 3; 1915: 252). See Taschek (2008) and Greimann (2014) for discussion.

${ }^{53}$ The latter reading is much more common, see e.g. Burge (1992: 315). See Linnebo (2003) for criticism.
} 
agency (we somehow succeed in performing an act which immediately consigns us to insanity). ${ }^{54}$

If we instead opt for a content-constitutive thesis, we can then more plausibly say that in cases of hesitancy (or outright denial) what is lost is not agency but content. 55 The claim now is that in entertaining the thought that a given BLL is invalid we are suffering from an illusion of understanding. We are not really thinking a determinate thought at all. ${ }^{56}$ It merely seems as if we do.

Suppose we grant that content-constitutivity does a better job of explaining BLL-denial. Even with this result in the bag, however, we will still be unable to address the two problems that I anticipated at the start of the section.

First, constitutivity claims, however flavoured, fail to answer the normativity question. If BLL are the conditions for the possibility of thought-content or of agenthood (of being a thinker, of being a judger), their justification (and the demands they pose) will only be hypothetical, not categorical. BLL will tell us to abide by them if one wants to be an agent, if one wants to be capable of having thoughts, if one cares for truth. But what is gained by these claims? They only make sense to someone who already is an agent, capable of entertaining thoughts, caring for truth (and doing so for the right reasons too). They do not explain why one should accept BLL, they would not move someone who is wilfully disregarding them because wholly disengaged from the project of agenthood. 57

Secondly, and relatedly, a constitutive account of BLL, like a sensebased account, obliterates the required distance between contentgrasp and content-evaluation. If BLL cannot coherently be doubted, if there is no activity that counts as doubting them, if doubting a BLL is tantamount to not having a thought at all, then it's again unclear

\footnotetext{
${ }^{54}$ For claims along these lines see e.g. Korsgaard (2008: 61) and Davidson (1985: 195-6).

${ }^{55}$ Under the loss of agency view, Frege himself, in his pre-1902 state, should count as a logical alien, a non-reasoner that somewhat miraculously retained enough critical faculties to understand Russell's letter and take remedial action.

${ }^{56}$ The content-constitutivity reading is supported by some textual evidence. According to Frege (1976: 127), asserting the negation of a false thought makes the content that we'd putatively be entertaining "strictly speaking incomprehensible". In the case of logically false thoughts, assertion would make them widersinning, counter-sensical, almost "lacking in content" (1923b: 393). Inconsistentist theorists of meaning embrace this result. See Eklund (2002), Patterson (2007b,a), Azzouni (2006, 2007), Scharp (2007), Armour-Garb (2007).

${ }^{57}$ See e.g. Lavin (2004), Enoch (2006, 2011), Ferrero (2012) and Shah (2010).
} 
that we can make any sense of the notion of reflective scrutiny over our practices. Constitutivity theses simply rule out hesitation with respect to BLL, for in hesitating we exit the space of Reason (either by losing agency or by losing content, and hence precipitating into nonsense)-indeed, hesitation has itself become a nonsense concept.

And so we have reached, yet again, an impasse. To escape it, we need to regain the space needed for the normative evaluation of BLL. But how? Let us now explore a proposal that does carve out such a space by uniting the various strands considered so far.

\section{Frege's Pragmatic Foundationalism}

So far, we have considered epistemologies of BLL firmly in keeping with the all-out foundationalist mould of classic rationalism. Within this tradition, the guiding principle is that there is a class of basic truths and that we apprehend them, by whatever means, singly. The grasp is atomic, as far as each law is concerned, and wholly grounded in its content-the different accounts we considered differed only with respect to the mode and character of that act of grasping.

But there is arguably another streak in Frege. There is, that is, a pragmatic twist on rationalism brought about by Frege's insistence, reiterated at the end of the preface to Grundgesetze, that we evaluate truths by testing them for fruitfulness. ${ }^{58}$

To make full sense of this proposal, it is helpful to heed a distinction between BLL-grasp and BLL-evaluation. The accounts so far examined had for the most part attempted to do away with this distinction so as to satisfy the immediacy desideratum (in grasping BLL-content we were taken to be reaching an evaluative conclusion as well). If we now reinstate the distinction, we can then view the pragmatic component as being concerned, at least in the first instance, with the verification of the logicality of the principles adopted, rather than with their grasp. So, there is a grasp-phase, where self-evidence (however defined) plays a major individuating role. But then there is also an evaluative phase in which the chosen BLL are put to the test. We do proofs, we see how far they take us, we modify the class of BLL to suit our theoretical purposes (simplicity, surveyability, completeness and so forth) and then, and only then, we come to the conclusion that the

${ }^{58}$ See also e.g. Frege (1880/1881: 33): "fruitfulness is the touchstone (Prüfstein) of concepts". 
initial impression of subjective self-evidence is now sustained by the confirmation of their objective self-evidence. After exhaustive "roadtests", that is, we can finally be confident that everything is in order with the chosen system, and this "experimental" realisation gives us retrospective justification for our choice of BLL.59

There are several passages in Frege's work that do support the attribution of this sort of "hands-on" view that I propose to dub pragmatic foundationalism. ${ }^{60}$ Perhaps the most striking of all comes from Carnap's lecture notes, where Frege is said to have remarked that "too much weight is put on showing that a claim is evident: not enough on [the] web of inferences that supports it". ${ }^{61}$ The fruitfulness (and basicness) of our BLL is thus something that is verified experimentally, and a posteriori. ${ }^{62}$

This approach tidily integrates several aspects of Frege's views regarding BLL while also providing a firm and highly articulate answer to our main question. BLL are self-evident (in the sense of selfstanding) but that they are so is something that can only be disclosed to reasoners when they attain the sort of full understanding that can only be attained once one is fully conversant with a system of proof. ${ }^{63}$

Self-evidence, then is both the starting and the end point of justification. Moreover, the way we get from one end to the other is a highly illuminating (and rationally mandated) journey. Accordingly, on this suggestion when logic gives out it is not epistemology per se that takes over but rather methodological pragmatism.

${ }^{59}$ See $G G$ (vii), Frege (1897b: 235). The retrospective justification envisaged here obtains in virtue of highly general features of rational deductive practice. By verifying that our system does exactly what it was designed to do, we gain insight into the privileged status of the laws that we had treated as epistemically foundational. On this view, theories are reasons for believing in the axioms. See also the intrisinc/extrinsic justification distinction in Maddy (2011: ch. V, \$4).

${ }^{60}$ See the discussion in Burge (1998), Jeshion (2001: 969), Ruffino (2002) and Reck (2007).

${ }^{61}$ Reck and Awodey (2004: 138).

${ }^{62}$ Note the striking similarities to Whitehead and Russell (1910/1997: v). The experimental nature of the verification in no way impinges on the a priori status of the terminal justification. The evaluative-phase is required because of our cognitive limitations, but the justification-makers that we eventually uncover remain firmly a priori.

${ }^{63}$ Gabriel's (1996) proposal that for Frege BLL-justification is some sort of meta-comment on the chain of reasons revealed by the Begriffsschrift proofs is a form of pragmatic foundationalism too (p. c.), and perhaps similarly for Weiner's (2001: 175) claim that it is understanding of the conceptscript that gives us epistemic access to the truth of BLL and Sullivan's (2004: 738) suggestion that BLL-justification flows from "reflective appreciation of the adequacy of a completed structure of justification” (my emphasis). 
Yet another problem now arises, however. On reflection, it seems as if under this proposal logic hasn't given out after all. For in testing for fruitfulness (and other familiar theoretical virtues) surely we must employ some principles of logic. For instance, there must be some ranking principle that will state which system (i.e. which choice of BLL) would be preferable and on what grounds. Consider for example one of Frege's many experimentally-flavoured remarks: "computation must quickly bring to light any flaw in the concept formations". ${ }^{64}$ Suppose we find a flaw in concept-formation: which part of the theory gets modified and on what basis? Do we revise the rules of inference, the axioms, the sub-structural rules, or some fundamental concept underlying the entire construction (as was the case following the post-1902 upheaval)? And what logical principles do we use to do our housekeeping? The worries here should be familiar from the Quinian onslaught on Carnap, as well as from powerful criticism of Quine's own Two Dogmas. ${ }^{65}$

In short, any judgement concerning BLL-fruitfulness will have to be reached via inference, it will have to employ, that is, properly logical means. And so pragmatic foundationalism, whilst tidily uniting all the marks of the logical in a unitary explanation of BLL-justification, has taken us back into the jaws of what Sheffer (1926: 228) called the logocentric predicament: "in order to give an account of logic, we must presuppose and employ logic". Circularity threats have once again come to the fore, blocking, or so it seems, our attempts at clarifying how logical laws are authoritatively given to us. ${ }^{66}$

And there is a further worry too, raised in Shapiro (2009: 190). Once we allow holistic elements into our epistemology, what is left of foundationalism? In short, is pragmatic foundationalism a form of foundationalism at all?

In the final section, I try to address both worries.

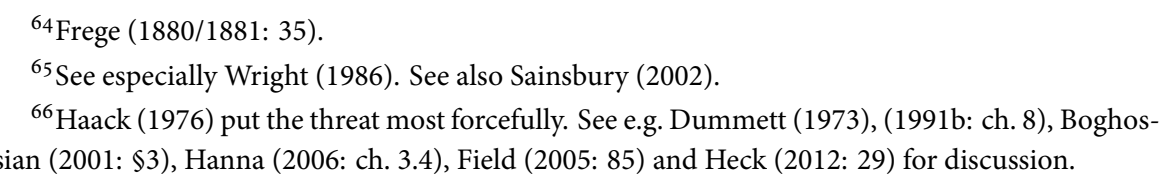




\section{A Dynamic Foundationalism?}

It looks as if all our attempts have somehow ended up in failure. Should we finally concede defeat and agree with those who read Frege as having argued for the "unintelligibility of a wholesale justification of logic"?67 Not quite yet. In the previous section, we regained the much-needed reflective space between BLL-grasp and BLL-evaluation. The price was justificatory circularity and the apparent dilution of Frege's foundationalism. I now want to see whether these two issues could be resolved. Towards that aim, I will outline a BLL-epistemology that, while undoubtedly unusual, is one that I think remains largely in keeping with Frege's views.

First, and for by-now familiar reasons, I want to keep open the gap between BLL-grasp and BLL-evaluation. I think one can remain relatively neutral as to which strategy to adopt re BLL-grasp. Sensegrasp is my preferred option, but it seems to me that constitutivity approaches could also be made to work. ${ }^{68}$ As far as BLL-evaluation is concerned, the methodologies outlined in the previous section will also do, with the provisos shortly to be discussed.

Secondly, I need to parry the accusation that as soon as the gap for BLL-evaluation is opened up and pragmatic considerations are allowed in, one has thereby sacrificed the purity of one's foundationalism. I think the accusation can be blocked by going externalist about content. I also think there are good independent reasons to attribute such a view to Frege. ${ }^{69}$ With that view on board, BLL-evaluation is only possible after one has unfolded that part of the content expressed by BLL which is not immediately transparent to a thinker. The content-externalist claim is that BLL are partly about the system, and hence their content cannot be available to reflection prior to the

\footnotetext{
${ }^{67}$ (George 2000: 14). See also e.g. Goldfarb (1979), Dreben and van Heijenoort (1986: 44-5), Floyd (1998), Hanna (2006: ch. 3).

${ }^{68}$ What would need showing to make constitutivity accounts work is how the purely epistemic project for which BLL are constitutive is inescapable because without it there would be no notion of evidence available, and hence no way for any form of subjecthood to come about (e.g. even Enoch's (2006) shmagent needs to have a notion of evidence in her conceptual repertoire in order to express disdain for the agency project, i.e. in order to be able to ignore or mishandle evidence). I discuss this option in my 'Evidentialism and Belief without Reasons' (ms.).

${ }^{69}$ Again, while I lack the space to do so here I defend the attribution in my 'Frege on content: hybrid theorist or externalist?' (ms.). My view is closer to Wiggins (1994) than to Burge (2005b: 57-8).
} 
construction of a system of proof. In this way, the pragmatic evaluation is not taken to be just an add-on element which is there to enable beings of limited cognitive resources to verify the good standing of the BLL. It is rather the only way in which that part of the content is made available to any thinker. In fact, I would want to argue (although I won't have the space to do so here) for a stronger point: it is the only way in which that part of the content comes into being.

The third thing that I need to do is to sketch the defence of a dynamic view of BLL-content that would provide one natural way to sustain the content-externalist claim and thus retain the foundationalist slant to Frege's conception of logic. The content-externalism at stake here is not just the claim that BLL-content is partly about the system, but that it is also partly about reasoning acts. Call it, if you wish, act-externalism. ${ }^{70}$

\subsection{The Dual Character of BLL}

To set the stage, let's recall that for Frege the foremost task in our reflective enquiry is "to isolate the logical". ${ }^{11}$ One of the lessons that I think we can now draw from the preceding pages is that there is however no royal road to the logical. We lack a single method that takes us to all BLL in the same way. The cluster theory sketched in $\$ 1.1$ gave a list of the marks of the logical that all BLL must satisfy. Each such mark will be satisfied in different ways, and to different degrees of explanatory priority by each BLL. ${ }^{72}$ There is therefore no single answer to the question of how BLL are given to us, for the sui generis justification of BLL is achieved through non-uniform methods. Each BLL will require a different sort of justification reflecting the specific range of inferential movements that it licenses (e.g. justifying the law of Identity will mobilise different resources than justifying the con-

\footnotetext{
$7^{70}$ The view is foreshadowed in e.g. Burge (2005b: 54) ("the connection between individuals' expressions (or thought events) and the contents that are thought depend, at least partly, on the individual's activities and capacities.") and in Gödel's (1961/?: 383) remark that the "clarification of meaning [of the axioms] consists in focusing more sharply on the concepts concerned by directing our attention [...] onto our own acts in the use of these concepts, onto our powers in carrying out our acts". In both cases, it seems as if the role of our reasoning acts is taken to play an enabling role. The view I sketch is instead intended to include those acts as part of the content of BLL.

${ }^{71}$ (Frege 1879/1891: 5).

${ }^{72}$ Indeed, as Burge (1998: §II) rightly notes, the explanations given in support of each BLL in Grundgesetze differ in method.
} 
ditional or Basic Law V).

Secondly, in thinking about the logical, we have so far been taking it to be somewhat static stuff. Granted, BLL are propositions. And yet they are also rules for the conduct of reasoning, for the direction of our intelligence; they tell us how to move between thoughts in ways that ensure proper regard for truth-preservation. I think we must do justice to the operational side of BLL. In fact, I maintain it is this dual character of BLL that holds the key to (part of) an answer to our question. ${ }^{73} \mathrm{BLL}$, that is, are both propositions and rules, they are both declarative and operational in character, they are static truths but also procedural instructions as to what to do with thoughts. This is after all, only to be expected, for in the realm of reference there are only truth-values and other logical objects; in turn, in the realm of sense there are only thoughts, the static order of truths, a realm of propositions. But logic, properly speaking, is about neither realm, since it is, rather, about movements among those thoughts; logic is, that is, about reasoning acts. Sure, those movements are constrained by the order of truths, but they only come into existence once BLL qua rules are exemplified by reasoners, reasoners that are to be characterised in complete abstraction from their psychological trappings. ${ }^{74}$ Accordingly, the three Fregean realms of objectively given entities need complementation by a fourth realm, the one determined by logic, a realm of rational movements between thoughts, a realm of reasoning acts.

So, we can now say that BLL are propositionally basic, in that no other proposition can justify them. However, when taken qua rules, BLL are epistemically improvable (and thus justifiable). Rules, as Sellars (1950: 155) proposed, are lived, not described. ${ }^{75}$ And we justify them first by their exemplification in acts of reasoning, and secondly by demonstrating that, so exemplified, they generate the appropriate class of consequences (as suggested by the pragmatic foundationalism model). Accordingly, BLL-qua-rules can be justified by some-

\footnotetext{
${ }^{73}$ MacFarlane (2002: 36) speaks of a "dual aspect" of BLL, but he thinks their operational side is implied by them rather than being part of their content broadly construed.

${ }^{74}$ This is, I think, a fully Fregean take on the matter, given that, as Frege (1882: 97) stressed, the purpose of the Begriffsschrift was "not to formally represent an abstract logic" but rather to "express a content" as precisely as possible. And as $B G \$ 13$ makes clear, the task of logic includes not just expressing a static content, but also making manifest "the relations of judgements to one another" (my emphasis).

${ }^{75}$ Sellars, though, opted for a version of the elucidatory strategy later defended by Weiner (see fn. 6 on p. 3). A similar view concerning epistemic norms is in Pollock and Cruz (1999: §3.4.3).
} 
thing epistemically stronger, namely, the entire order of truths and the structuring relations therein as disclosed by the exemplification of BLL-qua-rules. This, I think, should lessen one's worries re the logocentric predicament, since the operational character of BLL is not justified by logic but rather by the acts it licenses, by something that logic determines but does not wholly constitute-reasoners too are needed.

Now, how does this help with Shapiro's objection that the envisioned pragmatically derived justification is incompatible with foundationalism?

Well, here's a quick argument that I think should block the objection. For Frege (1906c: 338), logic has content; it is about "its own concepts and relations" such as "negation, identity, subsumption, subordination of concepts". Moreover, BLL contain, "as if in a seed", all of their consequences (those consequences are part of their content). ${ }^{76}$ But that content won't become available to a thinker until the construction of the system of logic is completed (a system that is, in effect, a structure of assertions supported by proofs). ${ }^{77}$ It follows, or so I'd argue, that the content of BLL is opaque to thinkers until the completion of the system. So, it's not that knowledge of the axioms depends (cannot be prior to) knowledge of the theorems. ${ }^{78} \mathrm{It}$ is, rather, that properly speaking knowledge of the axioms (i.e. of the BLL) is knowledge of the theorems. Note that the knowledge remains grounded in the axioms and that their full content is not available even to ideal reasoners until the system has been constructed (and

\footnotetext{
${ }^{76}$ Frege (1885b: 104; 1893/1998: II $\$ 147 ; 1914 b$ : 221). For the Kantian origin of this metaphor, see Kant (1781/1998: A834/B862), where the architectonic of pure reason is characterised as the art of (constructing) systems.

${ }^{77}$ Frege (1914a: 221, 242). Throughout the sequel, I'm taking the role of the system to go beyond the mere provision of enabling conditions. By contrast, e.g. Burge (1998: 337) takes it that understanding the inferential connections displayed by a system is a necessary condition for understanding the content of the BLL. The content of the latter, however, is not taken to include that of their consequences. Clearly, I'm taking Frege's "as if in a seed" metaphor more strictly instead.

${ }^{78}$ Shapiro (2009: 193). BG (\$13) draws a distinction between knowing the BLL and knowing, in addition, how those laws are interconnected. Crucially, Frege adds that it is only through this second, extended kind of knowledge that one can identify the class of BLL. This might sound like holism, but if my content-externalist claims go through, Frege's position would still count as foundationalist. What Frege calls knowledge of BLL is what I call knowledge of BLL-qua propositions. The extended kind of knowledge is knowledge of BLL-qua-rules, which in turn makes manifest those elements of BLL-content that, because they are partly about the system and partly about reasoning acts, cannot be fully captured in propositional terms.
} 
indeed given the inexhaustibility of the mathematical universe, properly speaking the content is never fully articulated). ${ }^{79}$ Moreover, it is only through the implementation of a system that the operational side of the BLL-content is disclosed (it is the system that makes it possible for genuinely rational thought-movements to occur).

If all this is on the right tracks, we can now answer Shapiro's worries. First, the methodological pragmatism is not an epistemological add-on that weakens the foundationalism. On the contrary. Because it contributes to the unfolding of the BLL-content, the pragmatically derived input is in fact strengthening the foundationalism. The holistic elements mobilised at the BLL-evaluation stage add nothing to the propositional content of BLL, that is, and they are not meant to "wholly replace" one's prior understanding of BLL. ${ }^{80}$ They don't provide, by themselves, justification either, for what they do is merely enable grasp of the full content of BLL, a content that in addition to including that of the theorems is also partly about the system and partly about reasoning acts. The foundationalism is therefore intact because unlike in the Quinian picture, it's not that the theorems provide support for the axioms (qua propositions). On the contrary: the epistemological priority still belongs to the axioms of whose content the theorems are but proper parts. Under holism, all that there is to the choice of axioms is that they fulfil the role reserved for them by the architectural argument. By contrast, on the view canvassed in this section axioms occupy that role in virtue of their content. And if so, the foundationalism hasn't collapsed into holism after all. ${ }^{81}$

\footnotetext{
${ }^{79}$ This is consistent with Frege's realism, because the way the content is determined is wholly independent of the reasoner. It remains true, that is, that "we grasp thoughts but we do not create them" (Frege 1906b: 198).

${ }^{80}$ Shapiro (2009: 192).

${ }^{81}$ I think that the passages in Frege (1879/1891: 3; 1897a: 126; 1915: 252) regarding the essence of logic provide further support for my attribution of the doctrine of act-externalism to Frege. We are first told that the essence of logic is given by the word 'true', that BLL unfold the content of that word. But then we are told that the sense of that word is semantically inert, that it makes no truth-conditional contribution under embedment. And the way this reveals the essence of logic, Frege adds, is precisely due to its failure to semantically express anything. It is, Frege concludes, the assertoric force that inherits the task which the word 'true' could not carry out. And assertoric force is something that belongs to acts of judgement, acts of reasoning. Only through those acts, then, can the essence of logic-what the BLL are about-be disclosed, precisely as per my theory. Note that under act-externalism, it is sense-grasp, in my extended sense, that secures BLL-grasp.
} 


\subsection{Content-recarving and Justification}

I've outlined an epistemology of BLL whereas each law contributes distinct elements that are jointly constitutive of rationality. I've tried to allay circularity worries by appealing to the dual character of BLL as both propositions and rules. I've also tried to defend a variety of pragmatic foundationalism that keeps justification essentially internal to the content of the BLL (the methodological pragmatism merely unfolds that content). Furthermore, the reflective scrutiny gap has been held in place by preserving the BLL-grasp/BLL-evaluation distinction. In effect, however, on this account BLL-evaluation is also BLL-grasp, to the extent that the full content of BLL only becomes available on completion of the evaluation procedure. But it is perfectly all right to speak of grasp of BLL ahead of their evaluation since what we initially grasp is their core propositional content together with their procedural content, while their full content is fully grasped, to the extent that it can be so grasped, only after the system is constructed.

We thus have the sketch of an answer to the question of how BLL are given to us. Recall though that the Urproblem facing us was how logical objects are given to us. In closing, I want to very briefly talk about the basic law that Frege entrusted-unwisely, as we all knowwith the task of solving that problem. What should we say about Basic Law V (BLV), then? Here's my suggestion.

As we saw, Frege's official position is that logic has the right to remain silent regarding transitions in thought that do not originate from other truths. I think that there are however some transitions local to a single thought, transitions that do not take us from one thought to another, but rather keep us within the same thought, and show it under a different description, as it were. I think we should say that according to Frege it is these privileged infra-contentual conceptual transformations that can generate logical objects. ${ }^{82}$ And their legitimacy cannot be supported by proof precisely because these reasoning acts are infra-contentual-there is no movement between

\footnotetext{
${ }^{82}$ I say 'can' because of the Bad Company Objection against abstractionist accounts of this kind. Some transformations (see e.g. Hale and Wright 2001: ch. 10) will create bogus objects because they result out of bad infra-contentual moves. Here I'm also assuming that the two sides of BLV express the same thought, a highly contentious claim indeed. See Ebert (forthcoming) for a recent discussion.
} 
thoughts, but only between different analyses of a single thought. Accordingly, Frege's suggestion is that we take the legitimacy of these single-thought transitions as a BLL:

[I]f one function (of first-level with one argument) and a second function are so constituted that both always have the same value for the same argument, then one may say instead: the value-range of the first function is the same as the valuerange of the second. We then recognise something in common to both functions and this we call the value-range both of the first function and of the second function. That we have the right so to acknowledge what is common, and that, accordingly, we can convert the generality of an equality into an equality (identity), must be regarded as a basic law of logic. ${ }^{83}$

That, then, is the genuine architectural requirement. For any logical knowledge to be in place, there must be a range of conceptual transformations that although not provable from other truths are nevertheless sanctioned by logic. The crucial point therefore is that it is logic itself that must force the acknowledgement of the required Umwandlung. ${ }^{84}$ But whence does the entitlement to take the transformation as a BLL flow? How does logic force that transformation on us?

Here, I think, the constitutivity component has got to set in: whenever and wherever any reasoner makes that transition, initiating the transformation between the conceptual decomposition on one side of (a properly sanitised version of) the law into the decomposition we find on the other side, then BLV will sanction the generation of logical objects, objects that, though independent of reasoners, exist only as generated through those transitions and must be recognised as such by whoever understands the concepts involved. Note that it is possible to understand the thought without making the transition (or without being aware of its possibility). But if one is presented with the transition, then proper understanding of the thought-content and of its possible internal articulations will indeed force the recognition of the logical legitimacy of the transition.

\footnotetext{
${ }^{83} G G$ (II $\left.\$ 146\right)$. See also $\$ 9$ in book I and Frege (1891: 142). Value-ranges are logical objects because they arise purely from concept-recarving and BLV gives an argument for that conclusion.

${ }^{84}$ This is stated most clearly in Frege (1906b: 181-2) (but see also (1897b: 235; 1924/25)): it is through our logical capacities that we get hold of extensions (objects associated with and generated from concepts). And logic "compels us almost ineluctably" to implement the transformation. On this proposal, BLL are immediate in the sense of "without inferential mediation", not immediate tout court.
} 
And so any reasoner, regardless of her psychological make-up, will be forced by logic to acknowledge the emergence of the logical objects thus disclosed. ${ }^{85}$ Crucially, the self-evidence with which these transitions strike us is logical self-evidence. In reflecting on the content of e.g. the right hand side of BLV, we come to realise that if two functions are such that their algorithms map arguments and values in exactly the same way, then there is some object which is the common outcome of the application of the two procedures, namely, their value-range. The reasoning, if correct, is entirely logic-based, because content, for Frege, is a purely logical notion, and content-recarving is content-internal movement. The universality thesis is thus preserved, and without intrusion from psychology.

Now, of course BLV is where Frege's ill-fated logicist enterprise came to a crushing halt in what Tait (1997: 246) has called "an act of recklessness" (the foolish assumption that concepts and objects can be paired one-to-one). ${ }^{86}$ In the end, the law failed both the test of self-evidence and of pragmatic evaluation (due to its flawed assumption that every algorithm determines a set-like extension, the law was overgenerating, positing objects for cases where none could be found).

I would however say that Frege's striking idea that conceptual recarving is a legitimate source of knowledge is left substantially unaffected by the paradox. Some properly regimented version of Basic Law $\mathrm{V}$ would vindicate that idea, and there is nothing that precludes in principle the possibility of some such regimentation. ${ }^{87}$

Earlier on, I said there was no single answer to the question of how BLL are given to us. At one level, however, we could say that there is. BLL are fully given to us via the construction of a system and via the reasoning acts that exemplify the thought-movements sanctioned by

${ }^{85}$ Again, see Frege (1906b: 181-2). The compellingness here is anything but primitive (in Peacocke's (1992) sense). It is in fact highly sophisticated.

${ }^{86}$ The (alleged) recklessness is due to Frege's disregard of Cantor's warnings. For a slightly less brutal assessment, see Parsons (1976: 134-5). Ebert and Rossberg (2009) dismiss Tait's accusation altogether.

${ }^{87}$ Note that the object-generating direction of BLV is not paradox-inducing. Three more points: i) as Frege himself noted (GG (II: 260)), the paradox goes deeper than BLV; ii) as e.g. Heck (1996) has shown, BLV is consistent in a predicative setting (and so it is not solely responsible for the paradox: e.g. unwise comprehension principles share the blame (Linnebo 2004), and a Fregean solution may well keep BLV-like principles and modify other moving parts in the account-e.g. restricting Rule 9 in $\$ 48$, vol. I, see e.g. Antonelli and May (2005) for one implementation). Of course, difficulties persist, see e.g. Sullivan and Potter (1997), Potter and Smiley (2002), Potter and Sullivan (2005), Sullivan (2007). But also see Milne's (2010) two novel ways of fixing BLV. 
BLL. It is BLL qua exemplified rules that power the transition to BLL qua propositions. When logic gives out, then, it is not epistemology on its own that takes up the slack. Rather, it is logic-driven reasoners that step in to complete the task. ${ }^{88}$

${ }^{88} \mathrm{I}$ am very grateful to the editors of this volume and to an anonymous referee for insightful comments that helped improve this paper. An early version of this paper was presented at the Early Analytic Group, Stirling, in October 2013. Thanks are due to the audience on that occasion, in particular to Peter Milne, Michael Potter, Stephen Read and Peter Sullivan. Additional thanks are owed to Dr. Gottfried Gabriel. Work on this paper was carried out during my Early Career Leverhulme Fellowship at Stirling. I am very grateful to the Leverhulme Trust and Stirling for their support in those three years. 


\section{References}

Antonelli, Aldo and May, Robert 2005. 'Frege's Other Program'. Notre Dame Journal of Formal Logic, 46, 1: 1-17.

Armour-Garb, Bradley 2007. 'Consistent Inconsistency Theories'. Inquiry, 50, 6: 639-654.

Audi, Robert 1999. 'Self-Evidence'. Noûs, 33, Supplement: Philosophical Perspectives 13: 205-228.

Azzouni, Jody 2006. Tracking Reason. Proof, Consequence, and Truth. Oxford: Oxford University Press.

2007. 'The Inconsistency of Natural Languages: How We Live with It'. Inquiry, 50, 6: 590-605.

Beaney, Michael 1996. Frege: Making Sense. London: Duckworth.

Beaney, Michael and Reck, Erich H. (eds.) 2005. Gottlob Frege: Critical Assessment. London: Routledge.

Bell, David 1987. 'Thoughts'. Notre Dame Journal of Formal Logic, 28, 1: 36-50.

Benacerraf, Paul 1981. 'Frege: The Last Logicist'. In Demopoulos, William (ed.) Frege's Philosophy of Mathematics. Cambridge, MA: Harvard University Press, pp. 41-67.

Béziau, Jean-Yves, Carnielli, Walter and Gabbay, Dov (eds.) 2007. Handbook of Paraconsistency. London: King's College Publications.

Blanchette, Patricia A. 2012. Frege's Conception of Logic. Oxford: Oxford University Press.

Boghossian, Paul 2001. 'How are Objective Epistemic Reasons Possible?' In Boghossian (2008), pp. 235-266.

2003. 'Blind Reasoning'. In Boghossian (2008), pp. 267-287.

2008. Content and Justification. Oxford: Clarendon Press.

BonJour, Laurence and Sosa, Ernest 2003. Epistemic Justification. Oxford: Blackwell.

Brandom, Robert 1994. Making It Explicit. Cambridge, MA: Harvard University Press.

2008. Between Saying and Doing. Oxford: Oxford University Press.

Broome, John 2013. Rationality Through Reasoning. Oxford: WileyBlackwell. 
Burge, Tyler 1992. 'Frege on Knowing the Third Realm'. In Burge (2005a), pp. 299-316.

1993. 'Content Preservation'. Philosophical Review, 102, 4: 45788.

1998. 'Frege on Knowing the Foundation'. In Burge (2005b), pp. 317-355.

2000. 'Frege on Apriority'. In Burge (2005a), pp. 356-387.

2003. 'Postscript to 'Frege on Apriority". In Burge (2005a), pp. $388-389$.

2005a. 'Disjunctivism and Perceptual Psychology'. Philosophical Topics, 33, 1: 1-78.

2005b. Truth, Thought, Reason. Essays on Frege. Oxford: Clarendon Press.

2012. 'Living Wages of Sinn'. In Cognition Through Understanding. Self-knowledge, Interlocution, Reasoning, Reflection. Oxford: Oxford University Press, pp. 556-593.

Conant, James 1991. 'The Search for Logically Alien Thought: Descartes, Kant, Frege, and the Tractatus'. Philosophical Topics, 20, 1: 115-180.

Davidson, Donald 1985. 'Incoherence and Irrationality'. In Problems of Rationality. Oxford: Clarendon Press, pp. 189-198.

Davies, Martin 1981. Meaning, Quantification, Necessity. London: Routledge \& Kegan Paul.

Dreben, Burton and van Heijenoort, Jean 1986. 'Introductory note to 1929, 1930 and 1930a'. In Feferman, Solomon (ed.) Collected Works, vol. I. Publications 1929-1936. Oxford University Press, pp. 44-59.

Dummett, Michael 1973. 'The Justification of Deduction'. In Truth and Other Enigmas. Cambridge, MA: Harvard University Press, pp. 290318.

1986. 'Frege's Myth of the Third Realm'. In Dummett (1991a), pp. 249-262.

1989. 'More about Thoughts'. In Dummett (1991a), pp. 289-314.

1990a. 'Frege and Husserl on Reference'. In The Seas of Language. Oxford: Clarendon Press, pp. 224-229.

1990b. 'Thought and Perception: The Views of Two Philosophical Innovators'. In Dummett (1991a), pp. 262-288. 
1991a. Frege and Other Philosophers. Oxford: Clarendon Press. 1991b. Frege. Philosophy of Mathematics. London: Duckworth. 1991c. The Logical Basis of Metaphysics. London: Duckworth.

Ebert, Philip A. forthcoming. 'Frege on Sense-Identity, Basic Law V, and Analysis'. Philosophia Mathematica.

Ebert, Philip A. and Rossberg, Marcus 2009. 'Cantor on Frege's Foundations of Arithmetic: Cantor's 1885 Review of Frege's Die Grundlagen der Arithmetik'. History and Philosophy of Logic, 30, 4: 341-348.

Eklund, Matti 2002. 'Inconsistent Languages'. Philosophy and Phenomenological Research, 64, 2: 251-275.

Enoch, David 2006. 'Agency, Shmagency: Why Normativity Won't Come from What Is Constitutive of Action'. The Philosophical Review, 115, 2: 169-198.

2011. 'Shmagency Revisited'. In Brady, Michael (ed.) New Waves in Metaethics. Palgrave Macmillan, pp. 208-233.

Evnine, Simon J. 2001. 'The Universality of Logic: On the Connection between Rationality and Logical Ability'. Mind, 110, 438: 335-367.

Ferrero, Luca 2012. 'Constitutivism and the Inescapability of Agency'. In Shafer-Landau, Russ (ed.) Oxford Studies in Metaethics. Volume 7. Oxford: Oxford University Press, pp. 303-333.

Field, Hartry 2000. 'Apriority as an Evaluative Notion'. In Truth and the Absence of Fact. Oxford University Press, pp. 361-387.

2005. 'Recent Debates about the A Priori'. In Gendler, Tamar Szabó and Hawthorne, John (eds.) Oxford Studies in Epistemology. Volume 1. Oxford: Clarendon Press, pp. 69-88.

Floyd, Juliet 1998. 'Frege, Semantics, and the Double Definition Stroke'. In Biletzki, Anat and Matar, Anat (eds.) The Story of Analytic Philosophy: Plot and Heroes. New York: Routledge, pp. 141-166.

Floyd, Juliet and Shieh, Sanford (eds.) 2001. Future Pasts: The Analytic Tradition in Twentieth Century Philosophy. Oxford: Oxford University Press.

Frege, Gottlob 1879. 'Begriffsschrift'. In van Heijenoort, Jean (ed.) From Frege to Gödel. Cambridge, MA: Harvard University Press, pp. 5-82. 1879/1891. 'Logic'. In Frege (1979), pp. 1-8.

$1880 / 1881$. 'Boole's logical Calculus and the Concept-Script. In Frege (1979), pp. 9-52. 
1882. 'Über die wissenschaftliche Berechtigung einer Begriffsschrift'. In Textor, Mark (ed.) Funktion-Begriff-Bedeutung. Göttingen: Vandenhoeck \& Ruprecht, pp. 70-76.

1884. The Foundations of Arithmetic. (1950) 2nd rev. edn. Oxford: Blackwell.

1885a. 'On Formal Theories of Arithmetic'. In Frege (1984), pp. $112-121$.

1885b. 'Über Formale Theorien der Arithmetik'. In Frege (1967/2011), pp. 103-111.

1891. 'Function and Concept'. In Frege (1984), pp. 137-156.

1892. 'On Sense and Meaning. In Frege (1984), pp. 157-177.

1892/1895. 'Ausführungen über Sinn und Bedeutung.' In Frege (1983), pp. 128-136.

1893/1998. Grundgesetze der Arithmetik. Jena/Hildesheim: Georg Olms Verlag.

1893/2013. Basic Laws of Arithmetic. Oxford: Oxford University Press.

1897a. 'Logic'. In Frege (1979), pp. 118-151.

1897b. 'On Mr. Peano's Conceptual Notation and My Own'. In Frege (1984), pp. 234-248.

_ 1899-1906. 'On Euclidean Geometry'. In Frege (1979), pp. 167169.

1906a. '17 Key Sentences on Logic'. In Frege (1979), pp. 174-75.

1906b. 'On Schoenflies: Die logischen Paradoxien der Mengenlehre.' In Frege (1979), pp. 176-183.

1906c. 'On the Foundations of Geometry: Second Series'. In Frege (1984), pp. 293-340.

— 1906b. 'A Brief Survey of my Logical Doctrines'. In Frege (1979), pp. 197-202.

-1914a. 'Logic in Mathematics'. In Frege (1979), pp. 203-250.

1914b. 'Logik in der Mathematik'. In Frege (1983), pp. 219-270.

-1915. 'My Basic Logical Insights'. In Frege (1979), pp. 251-252.

1918-19. 'Thought'. In Frege (1984), pp. 351-372.

1919. 'Aufzeichnungen für Ludwig Darmstaedter'. In Frege (1983), pp. 273-277.

1923a. 'Compound Thoughts'. In Frege (1984), pp. 390-406. 
1923b. 'Gedankengefüge'. In Frege (1967/2011), pp. 378-394.

1924/25. 'Sources of Knowledge of Mathematics and the mathematical natural Sciences'. In Frege (1979), pp. 267-274.

1967/2011. Kleine Schriften. Hildesheim, Zürich, New York: Georg Olms Verlag.

— 1976. Wissenschaftlicher Briefwechsel. Felix Meiner Verlag.

1979. Posthumous Writings. Oxford: Blackwell.

1980. Philosophical and Mathematical Correspondence. Oxford: Blackwell.

1983. Nachgelassene Schriften. Hamburg: Felix Meiner Verlag.

1984. Collected Papers on Mathematics, Logic, and Philosophy. Oxford: Blackwell.

Gabriel, Gottfried 1996. 'Frege's 'Epistemology in Disguise”. In Schirn, Matthias (ed.) Frege: Importance and Legacy. Berlin: Walter de Gruyter, pp. 330-346.

George, Alexander 2000. 'On Washing the Fur Without Wetting It: Quine, Carnap and Analyticity'. Mind, 109, 433: 1-24.

Gödel, Kurt 1944. 'Russell's Mathematical Logic'. In Feferman, Solomon (ed.) Collected Works, vol. II. Publications 1938-1974. Oxford University Press, pp. 119-141.

1951. 'Some Basic Theorems on the Foundations of Mathematics and their Implications'. In Gödel (1995), pp. 304-323.

1961/? 'The modern development of the foundations of mathematics in the light of philosophy’. In Gödel (1995), pp. 374-387.

1995. Collected Works, vol. III. Unpublished Essays and Lectures. Oxford University Press.

Goldfarb, Warren 1979. 'Logic in the Twenties: The Nature of the Quantifier'. Journal of Symbolic Logic, 44, 3: 351-368.

2001. 'Frege's Conception of Logic'. In Floyd and Shieh (2001), pp. 25-41.

2010. 'Frege's Conception of Logic'. In Potter and Ricketts (2010), pp. 63-85.

Greimann, Dirk 2014. 'Frege on Truth, Assertoric Force and the Essence of Logic'. History and Philosophy of Logic, 35, 3: 272-288.

Haack, Susan 1976. 'The Justification of Deduction'. Mind, 85, 337: 112119. 
1978. Philosophy of Logic. Cambridge: Cambridge University Press.

Haaparanta, L. and Hintikka, J. (eds.) 1986. Frege Synthesized. Reidel: Dordrecht.

Hale, Bob 2002. 'Basic Logical Knowledge’. In O’Hear (2002), pp. 279304.

Hale, Bob and Wright, Crispin 2001. The Reason's Proper Study. Essays towards a Neo-Fregean Philosophy of Mathematics. Oxford: Clarendon Press.

Hanna, Robert 2006. Rationality and Logic. Cambridge, MA: The MIT Press.

Harman, Gilbert 1986. Change in View: Principles of Reasoning. Cambridge, MA: The MIT Press.

Heck, Richard 2012. Reading Frege's Grundgesetze. Oxford: Clarendon Press.

Heck, Richard G. 1996. 'The Consistency of Predicative Fragments of Frege's Grundgesetze der Arithmetik. History and Philosophy of Logic, 17: 209-220.

Higginbotham, James 1998. 'Conceptual Competence'. In Villanueva, Enrique (ed.) Concepts, vol. 9 of Philosophical Issues. Atascadero, CA: Ridgeview, pp. 149-162.

Horwich, Paul 2010. Truth-Meaning-Reality. Oxford: Clarendon Press.

Jeshion, Robin 2001. 'Frege's Notion of Self-Evidence'. Mind, 110, 440: 937-976.

-2004. 'Frege: Evidence for Self-Evidence?' Mind, 113, 449: 131138.

Kant, Immanuel 1781/1998. Critique of Pure Reason. Cambridge: Cambridge University Press.

Korsgaard, Christine M. 1996. The Sources of Normativity. Cambridge: Cambridge University Press.

2008. The Constitution of Agency. Oxford: Oxford University Press.

Kremer, Michael 2001. 'The Purpose of Tractarian Nonsense'. Noûs, 35, 1: 39-73.

2010. 'Sense and Reference: the Origins and Development of the Distinction'. In Potter and Ricketts (2010), pp. 220-292. 
Lance, Mark and Kremer, Philip 1994. 'The Logical Structure of Linguistic Commitment I: Four Systems of Non-Relevant Commitment Entailment'. Journal of Philosophical Logic, 23, 4: 369-400.

1996. 'The Logical Structure of Linguistic Commitment II: Systems of Relevant Commitment Entailment. Journal of Philosophical Logic, 25, 4: 425-449.

Lavin, Douglas 2004. 'Practical Reason and the Possibility of Error'. Ethics, 114, 3: 424-457.

Lepore, Ernest and Ludwig, Kirk 2007. Donald Davidson's TruthTheoretic Semantics. Oxford: Clarendon Press.

Linnebo, Øystein 2003. 'Frege's Conception of Logic: From Kant to Grundgesetze'. Manuscrito, 26, 2: 235-252.

2004. 'Predicative Fragments of Frege Arithmetic'. The Bulletin of Symbolic Logic, 10, 2: 153-174.

Locke, John 1689/1975. An Essay Concerning Human Understanding. Oxford: Clarendon Press.

MacFarlane, John 2002. 'Frege, Kant, and the Logic in Logicism'. Philosophical Review, 111, 1: 25-65.

Maddy, Penelope 2011. Defending the Axioms. On the Philosophical Foundations of Set Theory. Oxford: Oxford University Press.

Milne, Peter 2010. 'Frege's Folly: Bearerless Names and Basic Law V'. In Potter and Ricketts (2010), pp. 465-508.

Nagel, Thomas 1997. The Last Word. New York and Oxford: Oxford University Press.

O'Hear, Anthony (ed.) 2002. Logic, Thought and Language. Cambridge: Cambridge University Press.

O’Neill, Onora 2000. Bounds of Justice. Cambridge: Cambridge University Press.

Owens, David 2000. Reason without Freedom. The problem of epistemic normativity. London and New York: Routledge.

Parsons, Charles 1965. 'Frege's Theory of Number'. In Mathematics in Philosophy. Selected Essays. Ithaca, New York: Cornell University Press, pp. 150-175.

1976. 'Some Remarks on Frege's Conception of Extension'. In From Kant to Husserl. Selected Essays. Cambridge, MA: Harvard University Press, pp. 117-130. 
Patterson, Douglas 2007a. 'Inconsistency Theories: The Significance of Semantic Ascent'. Inquiry, 50, 6: 575-589.

2007b. 'Understanding the Liar'. In Beall, JC (ed.) Revenge of the Liar. Oxford: Oxford University Press, pp. 197-224.

Peacocke, Christopher 1987. 'Understanding Logical Constants: A Realist's Account'. Proceedings of the British Academy, 73: 153-200.

1992. A Study of Concepts. Cambridge, MA: The MIT Press.

2004. The Realm of Reason. Oxford: Clarendon Press.

2008. Truly Understood. Oxford: Oxford University Press.

Pedriali, Walter B. 2012. 'Solvitur Ambulando. Meaning-constitutive Principles and the Inscrutability of Inference.' In Novaes, Catarina Dutilh and Hjortland, Ole Thomassen (eds.) Insolubles and Consequences. Essays in Honour of Stephen Read. London: College Publications, pp. 163-185.

Pollock, John L. and Cruz, Joseph 1999. Contemporary Theories of Knowledge. 2nd edn. Lanham: Rowman \& Littlefield Publishers.

Potter, Michael and Ricketts, Tom (eds.) 2010. The Cambridge Companion to Frege. Cambridge: Cambridge University Press.

Potter, Michael and Smiley, Timothy 2002. 'Recarving Content: Hale's Final Proposal'. Proceedings of the Aristotelian Society, 102: 351-354.

Potter, Michael and Sullivan, Peter 2005. 'What's Wrong with Abstraction?' Philosophia Mathematica, 13: 187-193.

Priest, Graham 2006. Doubt Truth to be a Liar. Oxford: Clarendon Press.

2007. 'Reply to Slater'. In Béziau et al. (2007), pp. 467-476.

Priest, Graham, Beall, JC and Armour-Garb, Bradley (eds.) 2004. The Law of Non-Contradiction. New Philosophical Essays. Oxford: Clarendon Press.

Quine, Willard V. 1970. Philosophy of Logic. 2nd (1986) edn. Cambridge, Mass.: Harvard University Press.

Reck, Erich H. (ed.) 2002. From Frege to Wittgenstein. Oxford: Oxford University Press.

Reck, Erich H. 2007. 'Frege on Truth, Judgment, and Objectivity'. In Greimann, Dirk (ed.) Essays on Frege's Conception of Truth. Grazer Philosophische Studien, Amsterdam, New York: Rodopi, pp. 149173. 
Reck, Erich H. and Awodey, Steve (eds.) 2004. Frege's Lectures on Logic. Carnap's Student Notes 1910-1914. Chicago and La Salle, Illinois: Open Court.

Ricketts, Thomas 1985. 'Frege, the Tractatus, and the Logocentric Predicament'. Noûs, 19, 1: 3-15.

1986. 'Objectivity and Objecthood: Frege's Metaphysics of Judgement'. In Haaparanta and Hintikka (1986), pp. 65-95.

1996. 'Logic and Truth in Frege'. Proceedings of the Aristotelian Society, Supplementary Volumes, 70: 121-140.

- 1997. 'Truth-values and Courses-of-value in Frege's Grundgesetze. In Tait, William W. (ed.) Early Analytic Philosophy. Frege, Russell, Wittgenstein. Essays in Honor of Leonard Linsky. Chicago and La Salle, Illinois: Open Court, pp. 187-211.

Ruffino, Marco 2002. 'Logical Objects in Frege's Grundgesetze, Section 10'. In Reck (2002), pp. 125-148.

Russell, Bertrand 1903/1996. The Principles of Mathematics. London: Routledge.

Russell, Gillian 2008. Truth in Virtue of Meaning. A Defence of the Analytic/Synthetic Distinction. Oxford: Oxford University Press.

Sainsbury, R.M. 2002. 'What Logic Should We Think With?' In O'Hear (2002), pp. 1-17.

Scharp, Kevin 2007. 'Replacing Truth'. Inquiry, 50, 6: 606-621.

Sellars, Wilfrid 1950. 'Language, Rules and Behavior'. In Sicha, J. (ed.) Pure Pragmatics and Possible Worlds. The Early Essays of Wilfrid Sellars. Atascadero, CA: Ridgeview, pp. 129-155.

1954. 'Some Reflections on Language Games'. In Science, Perception and Reality. Atascadero, CA: Ridgeview, pp. 321-358.

Shah, Nishi 2010. 'The Limits of Normative Detachment'. Proceedings of the Aristotelian Society, 110, 3: 347-371.

Shapiro, Stewart 2009. 'We Hold These Truths to Be Self-evident: But What Do We Mean by that?' Review of Symbolic Logic, 2, 1: 175-207.

Sheffer, Henry M. 1926. 'Review of Principia Mathematica'. Isis, 8, 1: 226-231.

Shieh, Sanford 2002. 'On Interpreting Frege on Truth and Logic'. In Reck (2002), pp. 96-124.

Simons, Peter 1992. 'Why is There So Little Sense In Grundgesetze?' 
Mind, 101, 404: 753-766.

Slater, Hartley 2007. 'Dialetheias are Mental Confusions'. In Béziau et al. (2007), pp. 457-466.

Stanley, Jason 1996. 'Truth and Metatheory in Frege'. In Beaney and Reck (2005), pp. 109-135.

Sullivan, Peter 2002. 'On Trying to be Resolute: A Response to Kremer on the Tractatus'. European Journal of Philosophy, 10, 1: 43-78.

2004. 'Frege's Logic'. In Gabbay, Dov M. and Woods, John (eds.) Handbook of the History of Logic, vol. 3. The Rise of Modern Logic: From Leibniz to Frege. Amsterdam: Elsevier, pp. 671-762.

2005. 'Metaperspectives and Internalism in Frege'. In Beaney and Reck (2005), pp. 85-105.

2007. 'How Did Frege Fall into the Contradiction?' Ratio, 20, 1: 91-107.

2011. 'Is Logic Transcendental?' In Smith, Joel and Sullivan, Peter (eds.) Transcendental Philosophy and Naturalism. Oxford University Press, pp. 157-.

Sullivan, Peter and Potter, Michael 1997. 'Hale on Caesar'. Philosophia Mathematica, 5: 135-152.

Tait, William 1997. 'Frege versus Cantor and Dedekind: On the Concept of Number'. In The Provenance of Pure Reason. Essays in the Philosophy of Mathematics and Its History. Oxford: Oxford University Press, pp. 212-251.

Taschek, William W. 2008. 'Truth, Assertion, and the Horizontal: Frege on 'The Essence of Logic'. Mind, 117, 466: 375-401.

van Heijenoort, Jean 1967. 'Logic as Calculus and Logic as Language'. Synthèse, 17, 3: 324-330.

Weiner, Joan 1986. 'Putting Frege in Perspective'. In Haaparanta and Hintikka (1986), pp. 9-27.

1990. Frege in Perspective. Ithaca, New York: Cornell University Press.

2001. 'Theory and Elucidation. The End of the Age of Innocence'. In Floyd and Shieh (2001), pp. 43-65.

2002. 'Section 31 Revisited. Frege's Elucidations'. In Reck (2002), pp. 149-182.

2004. 'What was Frege Trying to Prove? A Response to Jeshion'. 
Mind, 113, 449: 115-129.

Whitehead, Alfred North and Russell, Bertrand 1910/1997. Principia Mathematica to ${ }^{\star} 56$. Cambridge: Cambridge University Press.

Wiggins, David 1994. 'Putnam's Doctrine of Natural Kind Words and Frege's Doctrines of Sense, Reference, and Extension: Can They Cohere?' In Clark, Peter and Hale, Bob (eds.) Reading Putnam. Oxford: Blackwell, pp. 201-215.

Williamson, Timothy 2003. 'Understanding and Inference'. Proceedings of the Aristotelian Society, Supplementary Volumes, 77: 249-293.

Wittgenstein, Ludwig 1914-16/1998. Notebooks 1914-1916. Oxford: Blackwell.

Wright, Crispin 1986. 'Inventing Logical Necessity'. In Butterfield, Jeremy (ed.) Language, Mind and Logic. Cambridge: Cambridge University Press, pp. 187-209. 